\title{
Health Beliefs and Patient Perspectives of Febrile Illness in Kilombero, Tanzania
}

\author{
Christine Hercik, ${ }^{1 *}$ Leonard Cosmas, ${ }^{2}$ Ondari D. Mogeni, ${ }^{3}$ Wanze Kohi, ${ }^{4}$ Sayoki Mfinanga,${ }^{4,5}$ Christopher Loffredo, ${ }^{6}$ and \\ Joel M. Montgomery ${ }^{2}$ \\ ${ }^{1}$ Georgetown University, Washington, District of Columbia; ${ }^{2}$ Division of Global Health Protection, Center for Global Health, US Centers for Disease \\ Control and Prevention (US CDC), Nairobi, Kenya; ${ }^{3}$ Centre for Global Health Research, Kenya Medical Research Institute, Nairobi, Kenya; \\ ${ }^{4}$ Muhimbili Research Centre, National Institute of Medical Research, Dar es Salaam, Tanzania; ${ }^{5}$ Muhimbili University of Health and Allied Science, \\ Dar es Salaam, Tanzania; ${ }^{6}$ Georgetown Lombardi Comprehensive Cancer Center, Georgetown University, Washington, District of Columbia
}

\begin{abstract}
This qualitative study assessed the knowledge and beliefs surrounding fever syndrome among adult febrile patients seeking health care in Kilombero, Tanzania. From June 11 to July 13, 2014, $10 \%$ of all adult ( $\geq 15$ years) febrile patients enrolled in the larger syndromic study, who presented with an axillary temperature $\geq 37.5^{\circ} \mathrm{C}$ and symptom onset $\leq 5$ days prior, were randomly selected to participate in an in-depth physician-patient interview, informed by Health Belief Model constructs. Interviews were audio recorded, translated, and transcribed. Transcripts were coded using NVivo Version 11.1, and the thematic content was analyzed by two separate researchers. Blood and nasopharyngeal/ oralpharyngeal specimens were collected and analyzed using both acute febrile illness and respiratory TaqMan Array Cards for multipathogen detection of 56 potential causative agents. A total of 18 participants provided 188 discrete comments. When asked to speculate the causative agent of febrile illness, $33.3 \%$ cited malaria and the other $66.6 \%$ offered nonbiomedical responses, such as "mosquitoes" and "weather." Major themes emerging related to severity and susceptibility to health hazards included lack of bed net use, misconceptions about bed nets, and mosquito infestation. Certain barriers to treatment were cited, including dependence on traditional healers, high cost of drugs, and poor dispensary services. Overall, we demonstrate low concurrence in speculations of fever etiology according to patients, clinicians, and laboratory testing. Our findings contribute to the important, yet limited, base of knowledge surrounding patient risk perceptions of febrile illness and underscore the potential utility of community-based participatory research to inform disease control programs.
\end{abstract}

\section{INTRODUCTION}

Although malaria infection may be a common cause of febrile illness in sub-Saharan Africa, with the recent decline in malaria transmission rates across the region, it is important to consider other non-malarial agents potentiating fever syndrome. ${ }^{1-8}$ Recent etiologic investigations of febrile illness in Tanzania have detected the prevalence of a variety of pathogens, including zoonoses, such as leptospirosis, brucellosis, salmonellosis, and Q-fever, and vector-borne pathogens, such as dengue virus, chikungunya virus, and Rift Valley fever virus. ${ }^{9-18}$ In Tanzania's Morogoro region, diseases such as acute respiratory infections (ARIs), urinary tract infections, and typhoid fever have also recently been reported. ${ }^{19-21}$ These agents may contribute to high morbidity and mortality in humans, and therefore, awareness of such acute febrile illness (AFI)-associated agents should be more fully evaluated among at-risk communities.

Patient perceptions of risk and local understanding of disease transmission can influence the health-seeking behaviors and efficacy of disease prevention strategies. ${ }^{9,22,23}$ The Health Belief Model (HBM) is one of the most widely used social cognition models to predict health behaviors and is founded on four key deterministic elements, including perceived susceptibility, perceived severity, perceived benefits of taking health action, and perceived barriers of taking health action. ${ }^{24,25}$ Health Belief Model constructs have been implemented in a wide array of community-based studies to evaluate disease knowledge and have underscored the importance of health beliefs in determining preventative measures. ${ }^{26,27}$ In general, these studies have been conducted

*Address correspondence to Christine Hercik, Global Infectious Disease Researcher, Georgetown University, 3700 O St. NW, Washington, DC 20057-0004. E-mail: cah227@georgetown.edu in areas where disease prevalence is well evaluated, and therefore, these surveys have been targeted, disease-specific investigations, focused toward pathogens of public health importance, such as malaria, dengue, and Rift Valley fever. ${ }^{28-32}$ Most research to date evaluating local perceptions of fever syndrome in sub-Saharan Africa have predominately been focused on surveying mothers to evaluate the ability to recognize symptoms of malaria in children or focused on surveying health-care providers to evaluate the ability to provisionally differentiate and diagnose etiologic agents of fever syndrome. ${ }^{33-38}$ In Tanzania, a country known for its large size and significant ecological diversity, disease prevalence varies by region, notably in terms of malaria prevalence. ${ }^{39} \mathrm{~A}$ recent study by Chipwaza et al., ${ }^{40}$ evaluating community knowledge of fever syndrome in an area of high malaria transmission in southern Tanzania, found that the overall knowledge of non-malarial febrile illness was low and fever was oftentimes synonymous with malaria. A communitybased study by Hertz et al., ${ }^{41}$ evaluating perceived causes of fever in a setting of low malaria transmission in northern Tanzania, also found malaria to be cited as the leading cause of febrile illness, along with a variety of other non-biomedical explanations, such as weather.

In Kilombero, Tanzania, a highly malaria-endemic area where humans are situated in close proximity to areas of increased wildlife biodiversity, there is limited awareness of local perceptions regarding febrile illness. To build on the current knowledge base evaluated at the community-level elsewhere in the country, we conducted a more targeted study evaluating perceptions of fever among febrile patients. In this regard, we used diagnostic techniques to identify the causative agents of disease, in addition to qualitative survey approaches to investigate patient knowledge of disease etiology and broader health beliefs among affected community members. 


\section{MATERIALS AND METHODS}

Research ethics. Ethical clearance for this study was obtained from the National Health Research Ethics SubCommittee of Medical Research Coordinating Committee at the National Institute for Medical Research (NIMR/HQ/R.8a/ Vol.IX/1735) in Tanzania, and the U.S. CDC, Center for Global Health (CGH HSR 2014-118). A written informed consent was obtained from each participant before the interview. The participants were assured of anonymity in the analysis, presentation, and publishing of the data.

Study site. This surveillance project took place in Kilombero, Tanzania, a rural area where agro-industrial land use associated with sugarcane production has established a growing human population in close proximity to areas of significant wildlife biodiversity. The Illovo Sugar Limited Estate is the largest sugarcane production facility in Tanzania.

Kilombero (population $>321,000$ ) is located at an elevation of $300 \mathrm{~m}$ above the mean sea level, in the Morogoro region (population $>2$ million) of south-central Tanzania. ${ }^{42}$ The malaria transmission intensity in this region is high-overall community prevalence estimated to be $13 \%$ - with seasonal peaks following the long and short rain seasons. ${ }^{43}$ The Estate neighbors two national parks: Mikumi National Park and Udzungwa Falls National Park. Kilombero was selected because of its possession of intensive human activities with livestock and its proximity to wildlife from the bordering national parks, which has been identified as a susceptible area for zoonotic disease transmission. ${ }^{40,44}$

This hospital-based surveillance project was conducted at the Illovo Sugar Limited Estate Hospital (K1) and Clinic (K2). K1 Hospital is a private 80 -bed hospital, serving Illovo employees and dependents as well community members from nine surrounding villages, including Nyandeo, Msolwa Ujamaa, Mkula, Mangula, Kiberege, Msolwa Station, Ruaha, Kidogo Basi, and Luhembe. K2 Clinic is operational 5 days a week (Monday-Friday) and is only available to Illovo employees and their dependents.

Data collection. From June 11 to July 12, 2014, we used a mixed methods approach to evaluate fever syndrome in Kilombero, Tanzania. This qualitative study was nested within a larger surveillance project evaluating the cause and circumstance of febrile illness among patients seeking health care at Illovo K1 Hospital or K2 Clinic. Consenting patients with an axillary temperature of $\geq 37.5^{\circ} \mathrm{C}$ and symptomatic onset of $\leq 5$ days were eligible for enrollment and contribution of a whole blood sample. Subsequently, at the time of enrollment, if any adult patient was suffering from respiratory conditions (cough, chest pain, or sore throat) in addition to his/her febrile illness, then our laboratory technician collected a nasopharyngeal/ oralpharyngeal (NP/OP) swab. Blood and NP/OP specimens were analyzed using both AFI and respiratory TaqMan Array Cards (TACs) for multi-pathogen detection of 56 potential causative agents. In addition to the collection of biological specimens, we collected demographic and clinical data in standardized reporting forms.

Using qualitative methods, we assessed knowledge and beliefs surrounding fever syndrome among a randomly selected subset (10\%) of all adult febrile patients enrolled in the larger investigation. Over the course of 5 weeks, 18 adult febrile patients consented to participate in an in-depth, semistructured, physician-patient interview. To evaluate risk perceptions, we used HBM constructs to guide the development of our interview survey. ${ }^{45,46}$ All interviews were conducted based on a prepared semi-structured interview guide. Our interview guide, which comprised six semi-structured questions, probed not only patients' perception of individual disease status but also captured more broad-spectrum perceptions regarding risk beliefs (Table 4). During the interviews, notes were taken and conversations were digitally recorded. All interviews were held in Swahili, which is the most widely spoken language in the study area.

Data analysis. All data were entered electronically onto Samsung Galaxy Android tablets using an Open Data Kit platform. Statistical analyses were performed on the clinical and epidemiologic data using SAS version 9.3 software (SAS, Inc., Cary, NC).

Conversational soundtracks of interviews were electronically recorded onto the tablet devices. Interviews recorded in Swahili were translated to English and then back-translated to ensure accuracy of transcription. For quality control, random transcript segments were selected and compared against audio recordings, and were found to be accurate. After transcription and cleansing, the transcripts were converted to Rich Text Format and imported into NVivo software, version 11.1 (QSR International Pty. Ltd., Doncaster, Australia) for coding and categorization.

Responses to each question were analyzed separately, using a formalized content analysis approach to identify key themes relating to the HBM constructs. In this manner, direct comments could be highlighted, coded, and organized in NVivo so that overall connections and interpretations could be established.

To ensure accuracy and eliminate potential interpretation bias, two reviewers separately interpreted the data. In this approach, reviewers first carefully read and reread response narratives to fully understand the information provided. Second, they selected phrases verbatim from the transcript narrative, and assigned, or coded, each discrete comment to an emerging theme. Inter-coder reliability was calculated as the number of agreement divided by the total number of agreements and disagreements. In the case of differing thematic interpretations, discussion between the researchers took place until the final agreement was reached.

Laboratory analysis. All blood and NP/OP specimens collected were shipped to the Kenya Medical Research Institute laboratories in Nairobi, Kenya, for further diagnostic evaluations using a syndromic TAC diagnostic platform for the purposes of multi-pathogen detection of specimens. The TAC system is a 384-well multiplex, microfluidic, real-time quantitative PCR assay that is used to detect one or more biomarkers for a variety of bacterial, viral, and parasitic pathogens known to be common causative agents of a designated clinical syndrome (i.e., AFI, respiratory illness, diarrheal disease, and encephalitis). For the purposes of this study, we used both $\mathrm{AFI}$ and respiratory TAC assays. ${ }^{47,48}$

\section{RESULTS}

Participant characteristics. Of the 18 participants interviewed, 12 were men; this proportion was consistent with the overall enrollment in the larger sero-surveillance study, in which male enrollment (66\%) was more common than female enrollment. The majority of respondents $(77.8 \%)$ maintained a 
primary school-level of education or below. The median age of enrollment was 31 years (range 15-61 years). All participants were Tanzanian (Table 1).

All enrolled febrile patients contributed a blood sample for diagnostic analyses, and nine (50\%) of these patients, who also presented with respiratory conditions, contributed an NP/ OP specimen. Of all enrolled participants, 10 (55.5\%) were admitted for in-patient care and treatment.

Laboratory results. Diagnostic evaluations using both AFI and respiratory TAC identified nine different viral, bacterial, and parasitic agents among the 18 febrile patients contributing specimens. There were four $(20 \%)$ patients who did not present with biomarkers for any surveyed agent.

Acute febrile illness TAC was performed on all 18 febrile patients. Of these, we detected nucleic acid for Plasmodium in eight (44.4\%) individuals. Respiratory TAC was performed on nine febrile cases presenting with respiratory symptoms. Of these, we detected nucleic acid for eight different microbial agents, including adenovirus (1; 11.1\%), enterovirus (1; $11.1 \%)$, influenza B $(1 ; 11.1 \%)$, Haemophilus influenzae $(4$; $45 \%)$, Moraxella catarrhalis $(1 ; 11.1 \%)$, respiratory syncytial virus $(1 ; 11.1 \%)$, Staphylococcus aureus $(1 ; 11.1 \%)$, and Streptococcus pneumoniae (3; 33.3\%) (Table 2).

Interview results. The average time to conduct one interview was approximately 35 minutes. Overall, 18 participants provided 188 discrete comments. Responses were grouped by question and analyzed by two separate researchers. The calculated inter-coder agreement was $88 \%$. Final agreement was reached between the two researchers on the remaining $12 \%$ of discrepant responses. Table 3 summarizes the major thematic areas probed by each question and presents the key findings identified by the responses.

Knowledge of fever etiology. When our interviewers probed patients' perceptions of individual disease status, six (33.3\%) offered a biomedical response, whereas the remaining 12 $(66.6 \%)$ cited non-biomedical reasons, including "mosquitoes," "weather," "exhaustion," etc. Overall, the majority of respondents (66.6\%) denoted either malaria or mosquitoes as a causative agent of his/her fever syndrome.

TABLE 1

Epidemiologic characteristics of enrolled participants

\begin{tabular}{lcc}
\hline & \multicolumn{2}{c}{ Respondents } \\
\cline { 2 - 3 } \multicolumn{1}{c}{ Indicator } & $n$ & $\%$ \\
\hline $\begin{array}{l}\text { Gender } \\
\text { Male }\end{array}$ & 12 & 66.6 \\
Location of residence & 17 & 94.4 \\
$\quad$ Living on estate grounds & & \\
Education level & 0 & 0 \\
$\quad$ No formal education & 2 & 11.1 \\
Incomplete primary school & 12 & 66.6 \\
Completed primary school & 1 & 5.5 \\
Incomplete secondary school & 3 & 16.7 \\
Completed secondary school & 0 & 0 \\
Completed vocational school and/or university & & \\
Occupation & 6 & 33.3 \\
Sugarcane cutting & 3 & 16.6 \\
Weeding & 2 & 11.1 \\
Factory work & 0 & 0 \\
Managerial work & 0 & 0 \\
Security work & 3 & 16.6 \\
Other estate work & 4 & 22.2 \\
Not employed by the estate & & \\
Ownership of livestock & 18 & 100 \\
Yes & & \\
\hline
\end{tabular}

TABLE2

Proportion of enrolled participants with detected biomarkers for the examined viral, bacterial, and parasitic agents on acute febrile illness and respiratory TaqMan Array Cards

\begin{tabular}{lccc}
\hline \multicolumn{1}{c}{ Agent detected } & No. positive & No. tested & \% positive \\
\hline $\begin{array}{l}\text { Bloodstream agent } \\
\quad \text { Plasmodium }\end{array}$ & 8 & 18 & 44.4 \\
$\begin{array}{l}\text { Nasopharyngeal agents } \\
\quad \text { Adenovirus }\end{array}$ & 1 & 9 & 11.1 \\
$\quad$ Enterovirus & 1 & 9 & 11.1 \\
Influenza B & 1 & 9 & 11.1 \\
Haemophilus influenzae & 4 & 9 & 44.4 \\
Moraxella catarrhalis & 1 & 9 & 11.1 \\
Respiratory syncytial virus & 1 & 9 & 11.1 \\
Staphylococcus aureus & 1 & 9 & 11.1 \\
$\quad$ Streptococcus pneumoniae & 3 & 9 & 33.3 \\
\hline
\end{tabular}

As part of the clinical case report form, clinicians noted provisional diagnoses granted at point of care to all enrolled fever patients. Clinicians determine provisional diagnoses based on outputs of a malaria rapid diagnostic test and results from a thorough clinical examination. Of all 18 provisional diagnoses granted, nine (50\%) were malaria, four (22.2\%) were undifferentiated bronchitis, two (11.1\%) were undifferentiated ARI, two (11.1\%) were undifferentiated pneumonia, and one (5.5\%) was undifferentiated puerperal sepsis. Of the nine provisional malaria diagnoses, seven (77.8\%) were later confirmed by AFI TAC. Of the eight undifferentiated respiratory diagnoses (including bronchitis, ARI, and pneumonia), six (75\%) cases presented with biomarkers for at least one NP/OP agent as confirmed by respiratory TAC.

In comparing the overall considerations of patient fever etiology, as granted by patients, clinicians, and laboratory testing, we find a concurrence rate of $11.1 \%$. Table 4 provides a comparison of considerations of fever etiology, as determined by patients, clinicians, and laboratory testing for all enrolled participants.

Community health hazard beliefs. When our interviewers probed patient beliefs regarding health hazards, $72.2 \%$ of participants referenced malaria as the most significant health hazard facing the Kilombero community. After pooling response transcripts, the most frequently used word among respondents was "malaria" (12.6\%), followed by "fever" (5\%), "mosquito" (3.3\%), and "weather" (2.5\%).

Perceptions of severity and susceptibility to community health hazards. When interviewers asked participants to elaborate on their health hazard beliefs to better understand the perceived derivations of health hazards, participants offered 34 discrete comments. The most salient themes that emerged across the informant pool included 1) lack of bed net use, 2) misconceptions of bed net use, and 3) environmental susceptibility.

Lack of bed net use. Of the 34 discrete responses presented, nine $(26.5 \%)$ responses commented on the increased susceptibility to malaria, given the lack of appropriate bed net use. Respondents indicated that many people either do not have access to such bed nets or they choose not to use them.

"Malaria is such a problem because we don't sleep under the mosquito net" (female, 25 years old).

"There are so many people who don't have mosquito nets to protect them at night." (male, 25 years old). 
TABLE 3

Summary of interview questions, thematic areas probed, and key findings

\begin{tabular}{|c|c|c|c|}
\hline & Question & Thematic area probed & Key findings \\
\hline 1. & $\begin{array}{l}\text { What do you believe is the cause of } \\
\text { your fever today? }\end{array}$ & Knowledge of fever etiology & $\begin{array}{l}\text { One third of all participants provided a biomedical explanation. } \\
\text { Malaria and/or mosquitoes were the most common response } \\
(66.6 \%) \text {. } \\
\text { There is a concurrence rate of } 16.6 \% \text { among patient } \\
\text { self-diagnoses, clinician provisional diagnoses, and } \\
\text { laboratory-confirmed diagnoses. }\end{array}$ \\
\hline 2. & $\begin{array}{l}\text { What do you believe is the most } \\
\text { significant health threat facing your } \\
\text { community today? }\end{array}$ & Health hazard beliefs & $\begin{array}{l}72.2 \% \text { of participants referenced malaria as the biggest health } \\
\text { hazard. }\end{array}$ \\
\hline 3. & $\begin{array}{l}\text { Why do you believe } \mathrm{X} \text { (answer to } \\
\text { question } 2 \text { ) is the most significant } \\
\text { health threat facing your } \\
\text { community? }\end{array}$ & $\begin{array}{l}\text { Perceptions of severity and } \\
\text { susceptibility to health } \\
\text { hazards }\end{array}$ & $\begin{array}{l}\text { Major themes } \\
\text { Lack of bed net use } \\
\text { Misconceptions of bed nets } \\
\text { Environmental susceptibility }\end{array}$ \\
\hline 4. & $\begin{array}{l}\text { What has been the most effective } \\
\text { public health measure undertaken } \\
\text { in your community? }\end{array}$ & $\begin{array}{l}\text { Perceptions of effective } \\
\text { public health measures }\end{array}$ & $\begin{array}{l}\text { Major themes } \\
\text { Enhanced vector control } \\
\text { Successful health education campaigns } \\
\text { Barriers to treatment }\end{array}$ \\
\hline
\end{tabular}

"Others have the mosquito net but they choose not to use it." (male, 30 years old).

Misconceptions of bed nets. The final theme emerging in response to question \#3 encapsulated misconceptions regarding the use of bed nets. Bed nets were described as a potential source of infertility in men and a potential burden for users, given that nets were perceived to increase the temperature in the residence at night.

"People are not using nets with misconception that nets are the source of infertility to men." (female, 25 years old). "They say nets increases hot temperature in the room, people are already so hot at night, we can't take any more heat!" (male, 27 years old).
In addition, respondents referenced treatment seeking from traditional healers as another behavior which reduced patient utilization of an established health-care facility. Such "misdirection" of treatment-seeking behaviors toward traditional healers was viewed as a negative practice, deterring patients from obtaining conventional medical treatment for their illness.
"Misdirections to witch doctors. . instead of going to the hospital people goes to traditional healers." (female, 24 years old).

"The kind of people I live with, they believe in superstitions, they can't do anything without consulting witchdoctors." (female, 27 years old).

TABLE 4

Comparison of fever etiology considerations, as determined by patients, clinicians, and laboratory testing

\begin{tabular}{|c|c|c|c|}
\hline \multirow[b]{2}{*}{ Participant } & \multicolumn{3}{|c|}{ Considerations of fever etiology } \\
\hline & Patient perspective & Clinician perspective & TAC testing \\
\hline Participant \#1 & Mosquitoes & Pneumonia & $\begin{array}{l}\text { Adenovirus } \\
\text { Respiratory syncytial virus } \\
\text { Streptoccocus pneumoniae }\end{array}$ \\
\hline Participant \#2 & Due to a lump & Bronchitis & Unknown \\
\hline Participant \#3 & $\begin{array}{l}\text { Due to a wound and exhaustion } \\
\text { (overworked) }\end{array}$ & Malaria & $\begin{array}{l}\text { Plasmodium } \\
\text { Haemophilus influenzae }\end{array}$ \\
\hline Participant \#4 & Malaria & $\mathrm{ARI}$ & $\begin{array}{l}\text { Enterovirus } \\
\text { Moraxella catarrhalis }\end{array}$ \\
\hline Participant \#5 & Mosquitoes and exhaustion (overworked) & Malaria & Plasmodium \\
\hline Participant \#6 & Malaria & Pneumonia & Staphylococcus aureus \\
\hline Participant \#7 & Change of weather & Puerperal sepsis & Unknown \\
\hline Participant \#8 & Unknown & Upper respiratory tract infection (ARI) & $\begin{array}{l}\text { H. influenzae } \\
\text { S. pneumoniae }\end{array}$ \\
\hline Participant \#9 & Mosquitoes & Bronchitis & Unknown \\
\hline Participant \#10 & Due to bats in the sugarcane fields & Malaria & Plasmodium \\
\hline Participant \#11 & Exhaustion (overworked) & Malaria & Plasmodium \\
\hline Participant \#12 & Malaria & Malaria & Plasmodium \\
\hline Participant \#13 & Malaria & Bronchitis & $\begin{array}{l}\text { H. influenzae } \\
\text { S. pneumoniae }\end{array}$ \\
\hline Participant \#14 & Malaria & Malaria & Plasmodium \\
\hline Participant \#15 & Mosquitoes & Malaria & Unknown \\
\hline Participant \#16 & Mosquitoes & Bronchitis & $\begin{array}{l}\text { Plasmodium } \\
\text { Influenza B } \\
\text { H. influenzae }\end{array}$ \\
\hline Participant \#17 & Malaria & Malaria & Unknown \\
\hline Participant \#18 & Mosquitoes & Malaria & Plasmodium \\
\hline
\end{tabular}


Environmental susceptibility. Of all the responses, 16 (47\%) referenced certain environmental conditions, such as temperature, rainfall, and/or an abundance of standing water, as key features allowing for mosquito breeding that in turn perpetuates such high rates of malaria infection. Oftentimes, when respondents characterized their environment, they used the words "dirty" or "wet," as indicated below.

"I believe is due to high temperature because I come from Mbeya where the weather is cold, but here the temperature is high, so the change to the hot wet environment is the source of the mosquitoes which cause malaria." (male, 29 years old).

"I guess its because of the dirty environment. We have still water surrounding our houses, which is where you find the mosquitoes breeding." (male, 17 years old).

"I think it is because these mosquitoes that cause fever, sometimes they breed in the dirty environment, especially in the overflow of our latrine pits." (male, 33 years old).

Perceptions of effective community public health measures. Participants were then asked to share what they believed to be the most effective public health measure undertaken in the Kilombero community (question \#4). Positive responses yielded two main categories, including enhanced vector control measures and successful health education campaigns. A handful of respondents also replied to this question with a negative response, citing frustrations with barriers to treatment, including high pricing and poor dispensary services.

Enhanced vector control. Of the 38 responses to this question, 14 (36.8\%) determined successful vector control measures to be the most effective public health measure undertaken in the community. Respondents cited both mosquito net distribution and residential fumigation as the two most impactful vector control activities that have occurred in Kilombero. Although this theme yielded overall positive responses, it also underscored an important cue to action, as many respondents noted that bed nets have not been recently distributed, and are in fact in immediate need.

"They have been doing fumigation to our residences, this helps with the mosquito control." (female, 25 years old). "It might be distribution of mosquito nets, though they haven't done that recently." (male, 27 years old).

"I remember, it happened a certain time they gave us mosquito nets but nowadays only pregnant mothers are given." (male, 31 years old).

Successful health education campaigns. Many respondents also referenced health education as an effective mechanism for advancing public health in Kilombero. Many mentioned that both the Illovo Sugar Company and the Hospital facilitate these health education trainings on a routine basis, which help inform community members of important health measures to consider.

"The llovo company provides health education regularly to its community and its staff, this helps us a lot." (male, 17 years old).

"Provision of health education service, especially family planning services are so effective." (female, 48 years old).
Barriers to treatment. Although this question was intended to draw positive responses from participants, some individuals yielded negative attitudes in response, citing ongoing frustrations with various barriers to treatment. Participants referenced both high treatment costs and poor dispensary services as major impediments to the treatment-seeking behavior. Such negative attitudes, particularly in reference to the local dispensary, provide an additional cue to action, directing public health officials to a prominent source of treatment aversion.

\begin{abstract}
"There is new dispensary but the services are poor." (female, 26 years old).

"There are treatments though treatment costs are still so high!" (male, 35 years old).

"We have a new Nyandeo hospital which is good but the services at the dispensary are not good at all." (female, 28 years old).
\end{abstract}

\section{DISCUSSION}

In this study, we demonstrate low concurrence in speculation of fever etiologies across patients, clinicians, and laboratory testing. From the patient perspective, knowledge of fever etiology was low, and malaria was the only microbial agent cited as a cause of febrile illness. These findings are consistent with results from a study conducted by Hertz et al. $^{16}$ in northern Tanzania, which found significant discrepancy of actual and perceived etiologies of febrile illness. In our study, $66.6 \%$ of patients noted non-biomedical explanations of fever, such as "mosquitoes" and "weather." Non-biomedical reasoning for febrile illness has been demonstrated in several other studies conducted across subSaharan Africa, particularly in rural areas. ${ }^{23,34,48-50}$ Although half $(50 \%)$ of all patients enrolled in our study presented with respiratory symptoms, there was no mention from any participant of a possible respiratory tract infection. Recent studies characterizing febrile illness among children in Tanzania found that respiratory tract infections comprised the largest attributable fraction of clinical diagnoses among febrile patients, with respiratory distress serving as the strongest predictor of mortality. ${ }^{51-53}$ Additional studies assessing community perceptions of ARls found that fever was not among the most commonly identified symptoms associated with respiratory illness. ${ }^{54-57}$ Further education is needed to inform community members of the range of clinical signs of respiratory disease, including fever, to enhance a patient's ability to recognize symptoms and seek timely medical care.

From a clinical standpoint, limitations in laboratory diagnostic capabilities were evident in that clinical officers often provided undifferentiated diagnoses, such as ARI or bronchitis. Although localization of infection is an important first step in providing accurate diagnoses of febrile illness, without further testing capabilities at point of care, determination of appropriate treatment regimens, especially in terms of provision of antibiotics, is not possible. This finding underscores the need for enhanced diagnostic capabilities, particularly bacterial culture and antibiotic susceptibility capabilities for facilities that are at the secondary health-care level, to provide differential diagnoses that may inform the prescription of appropriate therapeutics. 
The most prominent theme emerging throughout this nested study was the perceived value and further need for enhanced vector control measures. When probed to provide reasoning for susceptibility and severity to health hazards, many respondents $(47 \%)$ referenced environmental conditions, such as temperature, rainfall, and/or an abundance of standing water, as key features perpetuating the severity of malarial infection in the community. Kilombero-a rural area that receives approximately $800 \mathrm{~mm}$ of rainfall annually-was most often characterized by respondents as "dirty" and "wet" which was perceived to be significant in allowing for mosquito breeding. ${ }^{43}$ Residential fumigation was viewed as an overall positive and impactful public health campaign undertaken to reduce mosquito populations around residential areas. Enhanced vector control measures targeting the elimination of areas of standing water, particularly surrounding the households and latrines as noted by respondents, are needed to further minimize mosquito breeding.

The lack of bed net use was viewed as another important factor increasing community susceptibility to health hazards. Our findings indicate that certain perceptions regarding potential impacts of bed nets, for example, male infertility or sleep discomfort, are prevalent in the community. Given that public health education is active and ongoing in Kilombero, as determined by responses regarding successful public health campaigns (question \#6), we recommend gearing such education toward shifting perceptions surrounding impacts of bed nets to encourage further community adoption of preventative practices. In addition, although many respondents applauded public health officials for distributing bed nets to community members, many respondents noted that bed net distribution had not occurred in recent years (except in the provision of nets to pregnant women), and should thus be considered a further cue to action for public health officials.

Health-care-seeking behaviors, notably the reliance on traditional healers, were cited as another factor provoking health challenges in the community. Respondents noted several barriers to conventional treatment, including high cost and poor dispensary services. These factors may in turn impact the treatment-seeking behavior and divert febrile patients from seeking modern medical countermeasures. Such occurrence is in agreement with findings from other studies evaluating health behavior, whereby researchers found that even though conventional medical approaches were preferred among patients, given that the cost of treatment was prohibitively expensive, patients turned to herbal remedies recommended by traditional healers. ${ }^{58-62}$ Appropriate care of treatable febrile illnesses will require inputs geared toward strengthening affordable drug availability. Public health officials, in conjunction with private sector partners, particularly Illovo Estate management, should further investigate ongoing public frustrations with local dispensary services and provide recommendations for improving access to treatment to enhance healthy living conditions of workers and residents.

This study had several limitations; most notably, the beliefs presented on behalf of these fever participants may not be representative of the beliefs of the entire Kilombero community; this evaluation is intended to be a formative study. Given that we only enrolled patients who were seeking conventional health care, we can assume that we did not capture beliefs from community members who prefer alternative approaches to managing febrile illness. A recent report, however, from the
Tanzanian Ministry of Health and Social Welfare, found that an estimated $60 \%$ of individuals seeking conventional healthcare services from hospital-based facilities in Tanzania also depended on traditional healers; thus, we may have captured opinions and beliefs from individuals who opt for a mixed approach to care and treatment. ${ }^{62}$ Furthermore, as seen across several survey-based qualitative studies, social acceptability bias may be a prominent confounding factor. Although we did capture the nationality status of all enrolled participants, we did not further investigate ethnic backgrounds or religious affiliations and, thus, did not consider how these factors could have changed the outcomes of our study. Further evaluation is needed to assess potential associations between ethnic and religious identities and health beliefs of this patient population. Clinical staff served as the prime interviewers for this study; thus, many patients may have been hesitant to provide non-biomedical replies to health-care providers in both identifying various causes of fever and providing reasoning for health hazard beliefs. In choosing HBM as our social cognition model for organizing and analyzing our dataset, we acknowledge that certain HBM constructs are more heavily represented by the study data, including perceived susceptibility to health hazards and perceived barriers of taking health action, as opposed to certain constructs that are less represented, including perceived severity of health hazards and perceived benefits of taking health action. However, given that the objective of this study was to better understand patient perceptions of health risks and beliefs surrounding healthseeking behaviors, this model was still successful in appropriately evaluating our dataset. Finally, although we believe that our 18 interviews allowed us to reach response saturation, we did not maintain a large enough sample size to determine significant discrepancies in responses based on age, gender, or any other sociodemographic factor.

In light of these limitations, there were also notable strengths to this study. To our knowledge this was the first formative study in Tanzania to assess health beliefs and risk perspectives among febrile patients themselves, and the first study to document etiologic determination from the perspective of patients, clinicians, and laboratory testing. Moreover, our rigorous laboratory methods allowed us to screen for up to 56 different etiologic agents of fever. To calibrate our quantitative assessment of seroprevalence and epidemiologic linkages among febrile participants, this nested study incorporated a qualitative investigation of patient health beliefs, thus allowing for a more holistic, mixed methods approach to the evaluation of fever syndrome in our study area.

\section{CONCLUSION}

Our findings demonstrate a significant knowledge gap between perceived and actual etiologies of febrile illness and, therefore, underscore the need for increased community awareness of other non-malarial agents potentiating fever syndrome. Proper management of febrile illness is largely dependent on the capacity of the health facility to perform accurate diagnosis through laboratory support and treatment of these illnesses. We highlight the need for enhanced diagnostic capabilities so that clinicians may provide a more accurate differential diagnosis of febrile illness and, therefore, recommend appropriate treatment recommendations. Overpriced treatment options and poor dispensary services may disincentivize febrile patients from seeking conventional medical 
care and treatment. Appropriate treatment of febrile patients will require inputs geared toward strengthening affordable drug availability and enhancing local dispensary services.

Our survey techniques, informed by the HBM, provided a platform for the assessment of perceived susceptibility and severity of health hazards in the community. This model provided a mechanism for us to identify perceived strengths and barriers of the present public health system, while allowing us to detect formative cues to future action. Our findings contribute to the important, yet limited, base of knowledge surrounding patient risk perceptions of febrile illness in a malaria-endemic setting of Tanzania. This study highlights important gaps in patient awareness of fever etiologies and underscores the potential utility of patientbased participatory research to inform disease control programming.

Received November 5, 2017. Accepted for publication March 16, 2019.

Published online May 20, 2019.

Acknowledgments: We would like to thank the Illovo management team, in particular the chief medical officer of Illovo Sugar Limited Estate Hospital, Dr. Sagumo Chotta, for granting us permission to conduct our study at his facility. We sincerely acknowledge the local clinical and laboratory officers of Illovo K1 Hospital and K2 Clinic, including Hamis Yusuf, Wilson Gyunda, Rogers Abisai, Bumija Mruma, and Felix Nyambuya, for providing exceptional contribution to this surveillance project. We would also like to thankEric Houpt and Jie Liu for providing technical assistance in TAC development and validation, and Daniel Macharia for providing geo-spatial mapping services for this project. This body of work served as part of the dissertation for $\mathrm{C}$. H. in pursuit of a PhD in the Global Infectious Disease Program at Georgetown University. We would like to thank her committee members for their constant advisement and unwavering support of her work, including J. M., C. L., Seble Kassaye, and Daniel Lucey.

Disclosure: The funding agency (USAID) had no part in the design of this study or analysis of results.

Disclaimer: The findings and conclusions of this study are those of the authors and do not necessarily represent the views of the U.S. CDC, the Kenya Medical Research Institute (KEMRI), the National Institute for Medical Research (NIMR), or Georgetown University.

Authors' addresses: Christine Hercik, Georgetown University, Washington, DC, E-mail: cah227@georgetown.edu. Leonard Cosmas and Joel M. Montgomery, Division of Global Health Protection, Center for Global Health, US Centers for Disease Control and Prevention (US CDC), Nairobi, Kenya, E-mails: leocosmas@gmail.com or ztq9@cdc. gov. Ondari D. Mogeni, Center for Global Health Research, Kenya Medical Research Institute, Nairobi, Kenya, E-mail: ondarim@gmail. com. Wanze Kohi and Sayoki Mfinanga, Muhimbili Research Center, National Institute of Medical Research, Dar es Salaam, Tanzania, E-mails: wanzejoyce@hotmail.com and gsmfinanga@yahoo.com. Christopher Loffredo, Georgetown Lombardi Comprehensive Cancer Center, Georgetown University, Washington, DC, E-mail: cal9@ georgetown.edu.

\section{REFERENCES}

1. Chizema-Kawesha E, Miller JM, Steketee RW, Mukonka VM, Mukuka C, Mohamed AD, Miti SK, Campbell CC, 2010. Scaling up malaria control in Zambia: progress and impact 2005-2008. Am J Trop Med Hyg 83: 480-488.

2. Manuel RJ, Reyes F, Tesfamariam A, 2005. Change in epidemiology of malaria infections in a rural area in Ethiopia. $J$ Travel Med 12: 155-156.

3. O'Meara WP, Bejon P, Mwangi TW, Okiro EA, Peshu N, Snow RW, Newton CR, Marsh K, 2008. Effect of a fall in malaria transmission on morbidity and mortality in Kilifi, Kenya. Lancet 372 : 1555-1562.
4. O'Meara WP, Mangeni JN, Steketee R, Greenwood B, 2010. Changes in the burden of malaria in sub-Saharan Africa. Lancet Infect Dis 10: 545-555.

5. D'Acremont V, Lengeler C, Genton B, 2010. Reduction in the proportion of fevers associated with Plasmodium falciparum parasitaemia in Africa: a systematic review. Malar J 9: 240.

6. Guerra CA, Gikandi PW, Tatem AJ, Noor AM, Smith DL, Hay SI, Snow RW, 2008. The limits and intensity of Plasmodium falciparum transmission: implications for malaria control and elimination worldwide. PLoS Med 5: e38.

7. Mmbando BP, Segeja MD, Msangeni HA, Sembuche SH, Ishengoma DS, Seth MD, Francis F, Rutta AS, Kamugisha ML, Lemnge MM, 2009. Epidemiology of malaria in an area prepared for clinical trials in Korogwe, north-eastern Tanzania. Malar J 8: 165

8. WHO, 2012. World Malaria Report. Available at: https://www.who.int/ malaria/publications/world_malaria_report_2012/report/en/. Geneva, Switzerland: World Health Organization.

9. Crump JA et al., 2013. Etiology of severe non-malaria febrile illness in northern Tanzania: a prospective cohort study. PLoS Negl Trop Dis 7: e2324.

10. Biggs HM et al., 2011. Leptospirosis among hospitalized febrile patients in northern Tanzania. Am J Trop Med Hyg 85: 275-281.

11. Bouley AJ et al., 2012. Brucellosis among hospitalized febrile patients in northern Tanzania. Am J Trop Med Hyg 87: 1105-1111.

12. Assenga JA, Matemba LE, Muller SK, Mhamphi GG, Kazwala RR, 2015. Predominant leptospiral serogroups circulating among humans, livestock and wildlife in Katavi-Rukwa ecosystem, Tanzania. PLoS Negl Trop Dis 9: e0003607.

13. Heinrich $\mathrm{N}$ et al., 2015. High seroprevalence for spotted fever group rickettsiae, is associated with higher temperatures and rural environment in Mbeya region, Southwestern Tanzania. PLoS Negl Trop Dis 9: e0003626.

14. Biggs HM, Hertz JT, Munishi OM, Galloway RL, Marks F, Saganda W, Maro VP, Crump JA, 2013. Estimating leptospirosis incidence using hospital-based surveillance and a populationbased health care utilization survey in Tanzania. PLoS Negl Trop Dis 7: e2589.

15. Biggs HM, Galloway RL, Bui DM, Morrissey AB, Maro VP, Crump JA, 2013. Leptospirosis and human immunodeficiency virus co-infection among febrile inpatients in northern Tanzania. Vector Borne Zoonotic Dis 13: 572-580.

16. Hertz JT et al., 2012. Chikungunya and dengue fever among hospitalized febrile patients in northern Tanzania. Am J Trop Med Hyg 86: 171-177.

17. Chipwaza B, Mugasa JP, Selemani M, Amuri M, Mosha F, Ngatunga SD, Gwakisa PS, 2014. Dengue and Chikungunya fever among viral diseases in outpatient febrile children in Kilosa district hospital, Tanzania. PLoS Negl Trop Dis 8: e3335.

18. Heinrich $\mathrm{N}$ et al., 2012. High seroprevalence of Rift Valley fever and evidence for endemic circulation in Mbeya region, Tanzania, in a cross-sectional study. PLoS Negl Trop Dis 6: e1557.

19. Mtango FD, Neuvians D, Korte R, 1989. Magnitude, presentation, management and outcome of acute respiratory infections in children under the age of five in hospitals and rural health centres in Tanzania. Trop Med Parasitol 40: 97-102.

20. Nadjm B, Mtove G, Amos B, Walker NF, Diefendal H, Reyburn H, Whitty CJ, 2012. Severe febrile illness in adult hospital admissions in Tanzania: a prospective study in an area of high malaria transmission. Trans R Soc Trop Med Hyg 106: 688-695.

21. D'Acremont V, Kilowoko M, Kyungu E, Philipina S, Sangu W et al., 2010. Etiology of fever in children from urban and rural Tanzania. Am J Trop Med Hyg 83: 16-17.

22. Comoro C, Nsimba SE, Warsame M, Tomson G, 2003. Local understanding, perceptions and reported practices of mothers/ guardians and health workers on childhood malaria in a Tanzanian district-implications for malaria control. Acta Trop 87: 305-313.

23. Chibwana Al, Mathanga DP, Chinkhumba J, Campbell CH Jr., 2009. Socio-cultural predictors of health-seeking behaviour for febrile under-five children in Mwanza-Neno district, Malawi. Malar J 8: 219. 
24. Rosenstock I, Stretcher V, Becker M, 1994. The health belief model and HIV risk behavior change. Preventing AIDS: Theories and Methods of Behavioral Interventions. New York, NY: Plenum Press, 5-24.

25. Janz NK, Champion VL, Strecher VJ, 2002. The health belief model. Glanz K, Rimer BK, Lewis FM, eds. Health Behavior and Health Education: Theory, Research, and Practice. San Francisco, CA: Jossey-Bass, 45-66.

26. Phuanukoonnon S, Brough M, Bryan JH, 2006. Folk knowledge about dengue mosquitoes and contributions of health belief model in dengue control promotion in northeast Thailand. Acta Trop 99: 6-14.

27. Thompson F, Caltabiano ML, 2009. The health belief model and dengue fever preventative behaviours: a pilot programme. Int $J$ Health Promot Educ 48: 0-19.

28. Sundararajan R, Mwanga-Amumpaire J, Adrama $\mathrm{H}$, Tumuhairwe J, Mbabazi S, Mworozi K, Carroll R, Bangsberg D, Boum Y, Ware NC, 2015. Sociocultural and structural factors contributing to delays in treatment for children with severe malaria: a qualitative study in southwestern Uganda. Am J Trop Med Hyg 92: 933-940.

29. Amuge B, Wabwire-Mangen F, Puta C, Pariyo GW, Bakyaita N, Staedke S, Kamya M, Olico-Okui, 2004. Health-seeking behavior for malaria among child and adult headed households in Rakai district, Uganda. Afr Health Sci 4: 119-124.

30. Wong LP, AbuBakar S, 2013. Health beliefs and practices related to dengue fever: a focus group study. PLoS Negl Trop Dis 7: e2310.

31. Wong LP, AbuBakar S, Chinna K, 2014. Community knowledge, health beliefs, practices and experiences related to dengue fever and its association with IgG seropositivity. PLoS Negl Trop Dis 8: e2789.

32. Shabani SS, Ezekiel MJ, Mohamed M, Moshiro CS, 2015. Knowledge, attitudes and practices on Rift Valley fever among agro pastoral communities in Kongwa and Kilombero districts, Tanzania. BMC Infect Dis 15: 363.

33. Orimadegun AE, llesanmi KS, 2015. Mothers' understanding of childhood malaria and practices in rural communities of IseOrun, Nigeria: implications for malaria control. J Fam Med Prim Care 4: 226-231.

34. Pilkington $\mathrm{H}$, Mayombo J, Aubouy N, Deloron P, 2004. Malaria, from natural to supernatural: a qualitative study of mothers' reactions to fever (Dienga, Gabon). J Epidemiol Community Health 58: 826-830.

35. Ibidapo CA, 2005. Perception of causes of malaria and treatmentseeking behaviour of nursing mothers in a rural community. Aust J Rural Health 13: 214-218.

36. Agu AP, Nwojiji JO, 2005. Childhood malaria: mothers' perception and treatment-seeking behavior in a community in Ebonyi state, South East Nigeria. J Comm Med Prim Health Care 17: 45-50.

37. Chandler Cl, Jones C, Boniface G, Juma K, Reyburn H, Whitty CJ, 2008. Guidelines and mindlines: why do clinical staff overdiagnose malaria in Tanzania? A qualitative study. Malar J 7: 53.

38. Baltzell K, Elfving K, Shakely D, Ali AS, Msellem M, Gulati S, Mårtensson A, 2013. Febrile illness management in children under five years of age: a qualitative pilot study on primary health care workers' practices in Zanzibar. Malar J 12: 37.

39. Oesterholt MJ, Bousema JT, Mwerinde OK, Harris C, Lushino P, Masokoto A, Mwerinde H, Mosha FW, Drakeley CJ, 2006. Spatial and temporal variation in malaria transmission in a low endemicity area in northern Tanzania. Malar J 5: 98.

40. Chipwaza B, Mugasa JP, Mayumana I, Amuri M, Makungu C, Gwakisa PS, 2014. Community knowledge and attitudes and health workers' practices regarding non-malaria febrile illnesses in eastern Tanzania. PLoS Negl Trop Dis 8: e2896.

41. Hertz JT, Munishi OM, Sharp JP, Reddy EA, Crump JA, 2013. Comparing actual and perceived causes of fever among community members in a low malaria transmission setting in northern Tanzania. Trop Med Int Health 18: 1406-1415.

42. NBS, 2011. 2010 Tanzania Demographic and Health Survey. Available at: https://dhsprogram.com/pubs/pdf/FR243/ FR243\%5B24June2011\%5D.pdf.
43. NBS, 2013. 2012 Population and Housing Census. Available at: http://catalog.insn.org/index.php/catalog/4618/download/ 58601.

44. Chengula AA, Mdegela RH, Kasanga CJ, 2013. Socio-economic impact of Rift Valley fever to pastoralists and agro pastoralists in Arusha, Manyara and Morogoro regions in Tanzania. Springerplus 2:549.

45. Burnham B, Wallington S, Jillson IA, Trandafili H, Shetty K, Wang $\mathrm{J}$, Loffredo CA, 2014. Knowledge, attitudes, and beliefs of patients with chronic liver disease. Am J Health Behav 38: 737-744.

46. Liu J et al., 2016. Development of a TaqMan array card for acutefebrile-illness outbreak investigation and surveillance of emerging pathogens, including Ebola virus. J Clin Microbiol 54: 49-58.

47. Kodani $\mathrm{M}$ et al., 2011. Application of TaqMan low-density arrays for simultaneous detection of multiple respiratory pathogens. J Clin Microbiol 49: 2175-2182.

48. Adetunji JA, 1991. Response of parents to five killer diseases among children in a Yoruba community, Nigeria. Soc Sci Med 32: 1379-1387.

49. Ahorlu CK, Dunyo SK, Afari EA, Koram KA, Nkrumah FK, 1997. Malaria-related beliefs and behaviour in southern Ghana: implications for treatment, prevention and control. Trop Med Int Health 2: 488-499.

50. Sabuni LP, 2007. Dilemma with the local perception of causes of illnesses in central Africa: muted concept but prevalent in everyday life. Qual Health Res 17: 1280-1291.

51. Reyburn $\mathrm{H}$ et al., 2004. Overdiagnosis of malaria in patients with severe febrile illness in Tanzania: a prospective study. BMJ 329: 1212.

52. Mahende C, Ngasala B, Lusingu J, Butichi A, Lushino P, Lemnge M, Premji Z, 2014. Aetiology of acute febrile episodes in children attending Korogwe District Hospital in north-eastern Tanzania. PLoS One 9: e104197.

53. D'Acremont V, Kilowoko M, Kyungu E, Philipina S, Sangu W, Kahama-Maro J, Lengeler C, Cherpillod P, Kaiser L, Genton B, 2014. Beyond malaria-causes of fever in outpatient Tanzanian children. N Engl J Med 370: 809-817.

54. Kauchali S, Rollins N, Bland R, Van den Broeck J; Child Health Group, 2004. Maternal perceptions of acute respiratory infections in children under 5 in rural South Africa. Trop Med Int Health 9: 644-650.

55. Muhe L, 1996. Mothers' perceptions of signs and symptoms of acute respiratory infections in their children and their assessment of severity in an urban community of Ethiopia. Ann Trop Paediatr 16: 129-135.

56. Kallander K, Nsungwa-Sabiiti J, Peterson S, 2004. Symptom overlap for malaria and pneumonia-policy implications for home management strategies. Acta Trop 90: 211-214.

57. Herman E, Black RE, Wahba S, Khallaf N, 1994. Developing strategies to encourage appropriate care-seeking for children with acute respiratory infections: an example from Egypt. Int $J$ Health Plann Manage 9: 235-243.

58. Ministry of Health and Social Welfare (MOHSW) (Tanzania and Zanzibar) and World Health Organization, 2007. Tanzania Service Availability Mapping 2005-2006.

59. Kahabuka C, Moland KM, Kvale G, Hinderaker SG, 2012. Unfulfilled expectations to services offered at primary health care facilities: experiences of caretakers of underfive children in rural Tanzania. BMC Health Serv Res 12: 158.

60. Willcox M, Bodeker G, 2004. Traditional herbal medicines for malaria. BMJ 329: 1156-1159.

61. Orem J, Mugisha F, Okui A, Musango L, Kirigia J, 2013. Health care seeking patterns and determinants of out-of-pocket expenditure for Malaria for the children under-five in Uganda. Malar J 12: 175

62. Kahabuka C, Kvale G, Moland KM, Hinderaker SG, 2011. Why caretakers bypass Primary Health Care facilities for child care a case from rural Tanzania. BMC Health Serv Res 11: 315. 